\title{
KUALIFIKASI SUMBER DAYA INSANI BERBASIS KOMPETENSI DAN INTEGRITAS DALAM AKAD MURABAHAH DI BMT PRIMA LUBUK SEBERUK KECAMATAN LEMPUING KABUPATEN OGAN KOMERING ILIR SUMATERA SELATAN
}

\author{
Muhammad Isnan \\ Sekolah Tinggi Ekonomi dan Bisnis Darussalam Ogan Komering Ilir \\ Email: jasdalasy3@gmail.com
}

\begin{abstract}
This research means to know qualification of human resources in BMT Prima Lubuk Seberuk in an effort increases the performance of the employees. This research used survey method by using qualitative data. The data collection technique which is used is direct interview with related one or informant. This research concluded that the development effort of the human resources quality of BMT Prima Lubuk Seberuk is dominated by the employee who is not syariah based. This thing provided BMT Prima lubuk seberuk to encrease the competence and the integrity of the employees by giving sustainable coaching to all of the employees for developing the competence and the integrity which is syariah based. The effort of developing the competence and the integrity in BMT Prima lubuk seberuk is using management assembling of human resources strategy among the are planning, recruitment process, giving motivation, education process and coaching. The result of the research showed that so far the development effort of human resources which is based on competence and integrity at BMT Prima Lubuk Seberuk went well. Observation result of researcher who found that the assets develompemnt is more and more and the trust phase of the customer at BMT Prima lubuk seberuk is more and more. This thing indicated that in order to fulfill the qualification standard of the employee which is competence and integrity based at BMT Prima Lubuk Seberuk for now is reputed to fulfill the service to the costemer in finances institute whic is syariah based like at BMT Prima.
\end{abstract}

Keyword: Qualification of Human Resources, Competency And Integrity, Murabahah, BMT Prima Lubuk Seberuk.

\section{Dasar Pemikiran}

Beberapa permasalahan lembaga keuangan syariah selama ini adalah terbatasnya sumber daya manusia atau didalam kajian islam disebut sumber daya insani. Minimnya sumber daya insani yang berkualitas menjadi kendala utama dalam membangun lembaga keuangan syariah yang berkualitas, akuntabel dan profesional, sesuai dengan nilai-nilai syariah. Ini ditunjukkan dari banyaknya sumber daya insani dilembaga 


\section{$24 \mid$}

Muhammad Isnan Kualifikasi Sumber Daya Insani Berbasis Kompetensi dan Integritas....

keuangan syariah yang belum memiliki pengetahuan dan pengalaman yang baik dalam menjalankan operasional lembaga keuangan syariah.

Terdapat sumber daya insani di lembaga keuangan syariah yang belum mampu memberikan pemahaman yang benar dan akurat mengenai produk-produk di lembaganya, sehingga berdampak pada keraguan calon nasabah untuk menggunakan produk dan layanan lembaga keuangan syariah dan akan mempengaruhi citra lembaga keuangan syariah tersebut. Kurang tersedianya SDI syariah sekarang ini memang telah menjadi masalah yang tengah dihadapi lembaga keuangan syariah. Tidak hanya sekedar persoalan kualitas saja, melainkan secara kuantitas juga menjadi sebuah persoalan yang perlu dibenahi (Nawawi, 2005: 7).

Pembenahan secara menyeluruh terhadap kualifikasi SDI dilembaga keuangan syariah menjadi sebuah keharusan, mengingat pentingnya pengembangan sumber daya insani dilembaga keuangan syariah sudah menjadi kebutuhan mendasar semua di lembaga keuangan syariah. Dalam perkembangannya, salah satu lembaga keuangan mikro syariah BMT (Baitul Maal Wat Tamwil) telah menyebar di berbagai daerah diseluruh Indonesia, salah satunya BMT Prima Lubuk Seberuk. Faktor yang membuat BMT Prima Lubuk Seberuk berkembang dan berhasil yaitu dengan jumlah nasabah yang menggunakan produk dan layanan di BMT tersebut relatif banyak. Namun kepuasan nasabah yang menggunakan produk dan layanan di BMT tersebut tergantung pada kinerja pegawai dalam memberikan pelayanan. Sedangkan pelayanan yang optimal tergantung pada tingkat profesionalisme sumber daya insani dalam mengelola dan menjalankan lembaga tersebut. Penelitian ini mengkaji bagaimana kualifikasi sumber daya insanidan upaya untuk meningkatkan sumber daya insani berbasis kompetensi dan integritas di BMT PrimaLubuk Seberuk dalam akad Murabahah.

\section{Metode Penelitian}

Penelitian ini merupakan penelitian deskriptif dengan menggunakan pendekatan kualitatif untuk mengetahui kualifikasi sumber daya insani berbasis komptensi dan integritas dalam akad murabahah di Baitul Mal Wat Tamwil (BMT) Prima. Hal ini selaras dengan salah satu tujuan penelitian deskriptif, yakni dimaksudkan untuk melakukan eksplorasi dan klarifikasi mengenai suatu fenomena atau kenyataan sosial 
dengan jalan mendeskripsikan sejumlah variabel yang berkaitan dengan masalah dan unit yang diteliti (Sanapiah, 2001: 20). Penelitian ini bertendensi memiliki ciri khas natural setting sebagai sumber data langsung, peneliti berstatus sebagai instrumen kunci (key instrument), bersifat deskriptif, lebih mementingkan proses dari pada produk, dan kecenderungan menganalisis data dengan cara induktif, sekaligus lebih mengutamakan makna.

\section{Pembahasan}

\section{Kualifikasi SDI Berbasis Kompetensi Dan Integritas di BMT Prima a) Kualifikasi Kompetensi SDI di BMT Prima}

Sumber daya insani memiliki posisi yang strategis didalam sebuah organisasi atau lembaga keuangan syariah. Tak terkecuali pada BMT Prima sesuai dengan penyampaian dari Bapak Muhammad Khoiri lembaga yang sudah di pimpin dari dulu sampai sekarang ini memiliki bentuk tersendiri mengenai hal perekrutan pegawai yang bersarjana syari'ah atau bukan.

Dalam pemenuhan standar kualifikasi pegawai yang seharusnya ada di BMT sesuai dengan karakteristik kompetensi adalah sebagai berikut :

1. Pengetahuan (knowledge), informasi yang dimiliki adalah bidang spesifik atau segala sesuatu pengetahuan yang dimiliki oleh seseorang.

2. Keterampilan, kemampuan dalam mengerjakan tugas fisik atau mental tertentu atau kecakapan seseorang dalam menyelesaikan tugas ataupun pekerjaan.

3. Motif (motives), sesuatu yang secara konsisten dipikirkan atau diinginkan orang yang menyebabkan tindakan.

4. Sifat (traits), karakteristik dan respon yang konsisten terhadap situasi atau informasi.

5. Konsep diri (selfconcept). Sikap, nilai-nilai, citra diri seseorang (Wibowo, 2013: $325)$.

Dari beberapa karakteristik tersebut diatas sepanjang pengamatan penulis, di lembaga keuangan BMT Prima belum sepenuhnya dapat tercapai, hal ini sesuai dengan wawancara penulis dengan General Manager BMT Prima Bapak Khoiri dan juga didukung oleh data yang penulis dapatkan dari objek penelitian. Dari beberapa pegawai 
26 | Muhammad Isnan Kualifikasi Sumber Daya Insani Berbasis Kompetensi dan Integritas...•

di BMT Prima mayoritas pegawai didominasi dari lulusan non perbankan syariah (Wawancara dengan General Manajer BMT Prima Senin 14 Januari Tahun 2019 di Kantor BMT Prima pada pukul 11:20 WIB). Ini dapat dilihat dari spesifikasi pegawai yang bekerja di BMT Prima dalam Tabel berikut:

Tabel : 1.1

Data Pegawai BMT Prima Lubuk Seberuk

\begin{tabular}{|c|l|l|l|}
\hline NO & \multicolumn{1}{|c|}{ NAMA } & \multicolumn{1}{|c|}{ BIDANG } & \multicolumn{1}{|c|}{ LULUSAN } \\
\hline 1 & Hariyanto, SE & Marketing & Sarjana ekonomi \\
\hline 2 & Siti Mar'atul Maghfiroh & Akuntansi & Akuntansi \\
\hline 3 & Rif'an Fauzi & Marketing & Madrasah Aliyah \\
\hline 4 & Eko Susanto, SPd. I & Penagihan angsuran & Sarjana Pendidikan Islam \\
\hline 5 & Abdul Karim. SPd & Penagihan angsuran & Sarjana pendidikan \\
\hline 6 & Sarlinda & Administasi umum & Madrasah Aliyah \\
\hline 7 & Fadhilatul Hasanah & Akuntansi & Akuntansi \\
\hline 8 & Imam Habib Soleh & Management & Madrasah Aliyah \\
\hline 9 & Hariyanto Setro & Management & Madrasah Aliyah \\
\hline
\end{tabular}

Data Internal BMT Prima Lubuk Seberuk Priode: 2017-2019

Dari data diatas dapat diketahui bahwa hampir keseluruhan pegawai BMT Prima bukan berlatar belakang dari pendidikan yang kualifikasi ekonomi syariah, yang memahami tentang aturan-aturan perbankan syariah, produk-produk beserta cara kerja maupun operasional dalam perbankan syariah.

Kurangnya pegawai yang berkualifikasi kompetensi di BMT Prima disebabkan oleh beberapa hal diantaranya:

1. Sedikitnya sumber daya insani yang berkualifikasi kompetensi syariah yang tersedia di sekitar lingkungan kerja BMT Prima. 
2. Kurangnya minat sumber daya insani untuk bekerja di lembaga keuangan mikro syariah karena masih dianggap lembaga keuangan syariah belum dapat bersaing dengan lembaga keuangan konvensional.

3. Lembaga keuangan syariah belum sepenuhnya dapat berkoordinasi dengan lembaga pendidikan yang berbasis ekonomi syariah untuk memenuhi kualifikasi pegawai di lembaganya (Wawancara Sarlinda, Kabidang SDA, di BMT Prima, 5 Maret 2019). Untuk menganggulangi kurangnya pegawai yang berkualifikasi dalam kompetensi ekonomi syariah, BMT Prima kemudian melakukan beberapa langkah untuk memenuhi standar pegawai yang bukan berlatar belakang pendidikan ekonomi syariah.

Beberapa langkah yang dilakukan oleh BMT Prima dalam pemenuhan kualifikasi kompetensi syariah dengan pegawai yang ada akan tetapi tidak memenuhi kualifikasi sumber daya insani syariah, adalah dengan melakukan pelatihan dan training dari Internal di BMT Prima, untuk memenuhi kebutuhan pegawai dalam jangka pendek.

BMT Prima telah menjadwalkan kepada pada (pegawai) pelatihan dalam setiap bulan dengan beberapa tema seperti fiqih muamalat, marketing, ke-BMT-an dan pengembangan diri. Pelatihan ini kami rasakan mempunyai dampak yang sangat positif karna kami menjadi lebih memahami tujuan dari BMT Prima (Wawancara, Fadhilatul Hasanah, Bagian Akuntansi BMT Prima 17 Januari 2019 di Kantor BMT Prima pada pukul 11:20 WIB).

Berdasarkan penjelasan tersebut, BMT Prima menetapkan bahwa kualifikasi syari'ah sangat penting di lembaga BMT Prima dengan membekali pegawai dari keilmuan perbankan syari'ah sesuai dengan teori dan praktek dilapangan, pembinaan inilah yang perlu dilakukan oleh lembaga BMT Prima, karena dalam permasalahannya di BMT Prima belum ada yang berlatar belakang perbankan syari'ah.

Kualifikasi merupakan keahlian yang sangat diperlukan untuk melakukan sesuatu pekerjaan, hal serupa juga dijelaskan oleh Bapak Muhammad Khoiri dalam BMT Prima diwajibkan bagi setiap sumber daya insani untuk belajar dan memahami pola kerja lembaga keuangan syari'ah, dalam lembaga BMT Prima mengambil orang-orang yang memiliki kualifikasi dan kompetensi yang bukan saja ahli dalam bidang ekonomi, keuangan dan perbankan, namun mereka harus memiliki kualifikasi dan kompetensi syari'ah. Dua sisi kualifikasi dan kompetensi ini dipadukan secara integral. Oleh karena 
28 | Muhammad Isnan Kualifikasi Sumber Daya Insani Berbasis Kompetensi dan Integritas...•

itu, sumber daya insani syari'ah harus selalu mengembangkan hal tersebut. Keahlian seseorang dalam bidang keuangan syari'ah akan terbangun secara baik untuk yang memenuhi kriteria jika ditemukan satu diantaranya SDI sebagai berikut:

1. Spesialis ilmu syari'ah yang memahami akad dan produk didalam lembaga keuangan syariah.

2. Spesialis ilmu ekonomi yang mengenal syari'ah, Mereka yang memiliki keahlian dalam syari'ah maupun ilmu ekonomi.

Kualifikasi kompetensi di lembaga keuangan BMT Prima didasarkan pada beberapa prinsip dasar sebagaimana yang telah penulis paparkan didalam kerangka teori yaitu: Memiliki kecerdasan intelektual atau Intellegent Quotient (IQ), Memiliki keceradasan emosional atau Emotiobal Quotient (EQ), Memiliki kecerdasan kreativitas atau Creativity Quotient (CQ), Memiliki kecerdasan spritiual atau Spritual Quotient (SQ) (Nawawi, 2005: 13).

\section{b) Kualifikasi Integritas SDI di BMT Prima}

Terdapat beberapa kualifikasi yang menjadi prinsip utama di BMT Prima dalam mengembangkan integritas para pegawai. Pengembangan kualifikasi integritas ini sangat penting mengingat lembaga keuangan khususnya BMT Prima sampai dengan saat ini masih menjadi yang terbesar di wilayah Kecamatan Lempuing Kabupaten Ogan Komering Ilir. Diharapkan dengan peningkatan integritas pegawai dilingkungan konator BMT Prima dapat memberikan dampak positif terhadap kualitas pegawai, peningkatan produktifitas dan pelayanan terhadap nasabah (Wawancara dengan General Manajer BMT Prima Senin 14 Januari 2019 di Kantor BMT Prima pada pukul 11:20 WIB).

Tujuan dari pengembangan ini sejalan dengan prinsip di lembaga keuangan syariah yang mengedepankan relegiutas, nilai kejujuran dan nilai motivasi. Di BMT Prima terdapat beberapa standar integritas yang diterapkan dalam rangka peningkatan mutu sumber daya insaninya.

Hal ini sejalan dengan beberapa kualitas integritas dan etos kerja Islami yang disampaikan Didin Hafiduddin dan Hendri Tanjung (2003: 40) di antaranya: Baik dan Bermanfaat, Al-Itqan (Kemantapan atau Perfectness), Al-Ihsan (Melakukan yang terbaik atau lebih baik lagi), Al-Mujahadah (Kerja keras dan Optimal), Tanafus dan 
Ta'awun (berkompetisi dan tolong-menolong) dan mencermati Waktu serta sejalan dengan pesan-pesan al-Qur'an dalam surah At-Taubah [9]: 105, al-Baqarah [2]: 215, alJumu'ah [62]: 10, Maryam [19]: 39, dan al-Mulk [67]: 15 (Zamzam dan Aravik, 2016: 97).

Kriteria-kriteria tersebut dapat terangkum dalam pengaplikasian yang dilakukan oleh BMT Prima. Prinsip dasar dalam standar kinerja pegawai yang selama ini diterapkan oleh BMT Prima sebagaimana tercermin dalam hasil wawancara penulis dengan Manajer BMT Prima 20 Januari Tahun 2019 di Kantor BMT Prima pada pukul 12:30 WIB, diantaranya:

1) Nilai keagamaan/Religiusitas

Religiusitas adalah hubungan pribadi dengan ilahi Yang Maha Kuasa, Maha Pengasih dan Maha Penyayang (Tuhan) yang berkonsekuensi hasrat untuk berkenan kepada pribadi yang ilahi itu dengan melaksanakan kehendak-Nya dan menjauhi yang tidak dikehendakinya (larangannya).

BMT Prima dalam menciptakan suasana releguitas di wilayah kantor baik pusat dan cabang melakukan kegiatan rutin berupa:

1. Sholat Dhuha berjama'ah di kantor yang dilakukan setiap pagi pada pukul 08:00 WIB.

2. Kajian fiqih kontomporer dilakukan oleh intern BMT Prima dan dalam tiga bulan sekali mengundang narasumber yang berkompeten dalam bidang kajian fiqh.

3. Infaq dan shadaqah. Dilakukan satu bulan sekali di akhir bulan (Wawancara dengan General Manajer BMT Prima Senin 14 Januari Tahun 2019 di Kantor BMT Prima pada pukul 11:20 WIB).

2) Nilai kejujuran

Kejujuran yang dimaksud disini adalah, BMT Prima sebagai lembaga keuangan syariah melakukan model transparansi dalam setiap melakukan transaksinya, pegawai mengungkapkan semua informasi yang diperlukan tentang kegiatan mereka, meskipun informasi yang ada adalah tidak menguntungkan. Transparansi ini dilakukan untuk membantu BMT Prima memenuhi antisipasi dari para pemangku kepentingan individu dan lembaga yang diharapkan untuk dapat melakukan transaksi simpanan maupun pembiayaan di BMT Prima. Dalam transparansi, BMT Prima cenderung 
30 | Muhammad Isnan Kualifikasi Sumber Daya Insani Berbasis Kompetensi dan Integritas....

mengungkapkan informasi keberlanjutan kegiatan utama mereka. BMT Prima juga mengungkapkan informasi yang menunjukkan bahwa kegiatan mereka tidak bertentangan dengan prinsip-prinsip ajaran Islam.

3) Nilai motivasi/kesemangatan.

BMT Prima menerapkan beberapa prinsip dalam memotivasi kerja pegawainya di antaranya:

a. Prinsip Partisipasi

Prinsip ini bermakna bahwa pegawai diberikan kesempatan ikut berpartisipasi bersama dalam menentukan tujuan yang akan dicapai oleh pemimpin. Bentuk keikutsertaan dalam berpartisipasi pegawai di BMT Prima adalah dengan menyertakan pegawai dalam menyelesaikan beberapa masalah yang muncul di BMT Prima seperti proses dalam perkadan dan penyelesaian keterlambatan pembayaran nasabah (Wawancara, Hariyanto, pegawai BMT Prima, 5 Maret 2019).

\section{b. Prinsip Komunikasi}

Memberikan informasi jelas, dan kredibel sehingga pegawai akan lebih mudah dimotivasi kerjanya untuk mencapai target yang sudah ditentukan oleh atasan. Bahkan dalam berkomunikasi antar pegawai dari seluruh lini struktural BMT Prima mengedepankan komunikasi kekeluargaan dalam artian tetap mengedepankan prosedur jabatan. Sikap kekeluargaan yang dibangun didalam jajaran pegawai terbukti dapat meningkatkan efektifitas kerja antar lini dalam jajaran seluruh pegawai di BMT Prima (Sarlinda. Bagian Administasi Umum. Wawancara di BMT Prima 5 Maret 2019)

c. Prinsip Mengakui Andil Bawahan

Manajer dalam hal ini sebagai pemimpin pelaksana di BMT Prima mengakui bahwa bawahan (pegawai) mempunyai andil dalam usaha pencapaian tujuan lembaga keuangan di BMT Prima. Dengan pengakuan tersebut, pegawai di BMT Prima ternyata lebih mudah dimotivasi kerjanya karena pegawai akan merasa ide dan gagasannya bisa diterima. Bahkan seluruh pegawai selalu diikutsertakan didalam setiap penanganan masalah dan problem yang muncul termasuk apresiasi yang diberikan BMT Prima apabila pegawai dapat memenuhi target pencapaian yang sudah ditentukan oleh BMT Prima (Wawancara Eko Susanto, Bagian Penagihan Angsuran BMT Prima, 5 Maret 2019). 
ISLAMIC BANKING Volume 5 Nomor 1 Edisi Agustus 2019 | 31

d. Prinsip Pendelegasian Wewenang

Dalam prinsip pembagian tugas di BMT Prima manajer memberikan otoritas atau wewenang kepada pegawai bawahan untuk sewaktu-waktu dapat mengambil keputusan terhadap pekerjaan yang dilakukannya, akan membuat pegawai yang bersangkutan menjadi termotivasi untuk mencapai tujuan yang diharapkan oleh pemimpin dan ini akan mempercepat proses pencapaian tujuan di BMT Prima. Dalam sistem pendelegasian ini BMT Prima akan tetap melakukan koordinasi untuk menjaga kelancaran dalam sebuah organisasi. Manajer akan berperan aktif memantau kinerja pegawai dari seluruh level.

\section{e. Prinsip Memberi Perhatian}

BMT Prima dalam selalu berupaya untuk memberikan perhatian terhadap apa yang diinginkan oleh pegawai, selain sebagai bentuk apresiasi kepada keryawan, perhatian ini bertujuan untuk mempererat kekeluargaan bukan hanya kepada para pegawai akan tetapi juga kepada segenap keluarga para pegawai, BMT Prima selalu membuat agenda silaturahim secara rutin ke rumah para pegawai secara bergilir (Wawancara dengan General Manajer BMT Prima di kantor pusat. Pada 16 Januari 2019 pukul: 10:00 WIB).

Ketiga prinsip dasar integritas di atas sampai saati ini tetap menjadi landasan kinerja bagi pegawai dan telah dibuktikan dengan capaian-capaian yang didapat BMT Prima selama ini.

\section{c) Pengembangan SDI di BMT Prima Lubuk Seberuk}

Adapun yang dilakukan oleh manajemen sumber daya insani dalam strategi pengembangan sumber daya insani di BMT Prima adalah:

1. Proses Perencanaan (Planning)

Dalam hal perencanaan, BMT Prima sudah memiliki standar mengenai kebutuhan pegawai di kantornya. Namun tetap disesuaikan dengan kebutuhan SDI dari pusat maupun Kantor Cabang (KC). Penambahan SDI terjadi jika bagian Sumber Daya Insani (SDI) menerima laporan dari kantor pusat atau Kantor Cabang yang menyatakan bahwa Kantor Cabang tersebut membutuhkan tambahan pegawai baru, atau jika terdapat perencanaan untuk ekspansi perusahaan di daerah lain. Dalam membuat perencanaan tersebut, bagian SDI akan melakukan koordinasi dengan operational officer di kantor 
cabang yang membutuhkan pegawai maupun dengan SDI lainnya mengenai pendistribusian SDI yang dibutuhkan.

\section{Proses Perekrutan (Recruitment)}

Lembaga ini memiliki sistem recruitment dengan spesifikasi-spesifikasi yang telah ditentukan. Untuk mendapatkan pegawai yang baik maka perusahaan melakukan seleksi dimulai ketika calon pegawai mengajukan surat lamaran pekerjaan ke BMT Prima, dan berakhir pada saat dilakukan keputusan pengangkatan. Adapun proses perekrutan calon pegawai pada BMT Prima didasarakan pada kebutuhan yang ada. Sumber perekrutan pada BMT Prima dibagi menjadi dua bagian, yaitu sumber internal perusahaan dan eksternal perusahaan.

a. Sumber Internal

Secara umum BMT Prima lebih mengutamakan perekrutan pada sumber internal sebelum membuka lowongan pekerjaan untuk pihak eksternal. Perekrutan pada sumber internal ini dilakukan dengan cara bagian SDI memberdayakan pegawai yang sudah ada, misalnya dengan cara mengubah status pegawai dari pegawai kontrak menjadi pegawai tetap, atau dengan cara mutasi atau rotasi pegawai.

b. Sumber Eksternal

Perekrutan dari pihak eksternal dilakukan melalui proses penyebaran informasi lowongan kerja dari pihak BMT Prima melalui media cetak dan radio atau menyebarkan brosur di tempat-tempat umum, khususnya bagi fresh graduate, serta tidak jarang dengan melihat daftar nama pelamar sebelumnya .

3. Pemberian Motivasi

Motivasi adalah proses mempengaruhi dan mendorong seseorang untuk menyelesaikan tujuan yang diinginkan dan menciptakan kegairahan kerja seseorang agar mereka mau bekerja sama. Dengan pemberian motivasi ini diharapkan sumber daya manusaia (pegawai) BMT Prima dapat termotivasi untuk selalu meningkatkan pengetahuan dan kualitas.

Ada dua metode motivasi yang dilakukan di BMT Prima Lubuk Seberuk antara lain; Pertama, Motivasi yang langsung diberikan pimpinan kepada bawahannya untuk memenuhi kebutuhan serta kepuasaanya. Sifanya khusus, seperti: pujian, penghargaan, tunjangan hari raya, bonus dan bintang jasa. Kedua, motivasi tidak langsung yang 
ISLAMIC BANKING Volume 5 Nomor 1 Edisi Agustus 2019 | 33

diberikan dalam bentuk fasilitas-fasilitas pendukung dan penunjang kinerja serta kelancaran tugas. Misalnya pemberian kendaraan yang baik bagi pegawai lapangan, mesin-mesin baru dan baik, ruangan kerja terang dan nyaman, suasana pekerjaan serasi, serta penempatan tepat bagi setiap pekerja. Motivasi tidak langsung besar pengaruhnya untuk merangsang semangat bekerja pegawai sehingga produktif.

4. Proses Pendidikan dan Pelatihan

Guna menghasilkan SDI yang handal dan kompoten BMT Prima memiliki komitmen tinggi terhadap peningkatan kualitas pekerja melalui beragam fasilitas pendidikan dan pelatihan (Diklat), terdiri: Program Pelatihan Berbasis Kompetensi dan integritas seperti core training, functional training, Behaviour Training dan Managerial Training.

Dalam melaksanakan program pelatihan dan pengembangan BMT Prima menggunakan teknik pendidikan dan pelatihan (diklat) yang meliputi:

a. Diklat On The Job

Diklat on the job adalah pelatihan yang diadakan oleh BMT Prima sendiri dan dilaksanakan sebagai bagian dari pelaksanaan kerja pegawai. Diklat on the job yang dilaksanakan berupa antara lain Rotasi Jabatan (Job Rotation), Latihan Instruksi Pekerjaan (Job Instruction Training), Magang (Apprentichesip), dan Pembekalan (coaching).

\section{b. Diklat Off The Job}

Diklat of the job adalah diklat yang dilaksanakan oleh BMT Prima sendiri ataupun dapat bekerjasama dengan pihak lain di luar lembaga keuangan BMT Prima. Pelaksanaan diklat ini adalah dalam waktu tertentu dengan membebastugaskan pegawai untuk sementara guna mengikuti program diklat. Diklat off the job dapat berupa antara lain

1) Pengembangan keperibadian

Pengembangan keperibadian dapat dilakukan untuk meningkatkan kinerja pegawai terutama dari aspek kepribadian (perilaku, moral, dan etika). Langkah yang dilakukan adalah:

a) Pengajian yang diadakan secara rutin, yaitu seminggu sekali setiap hari jum'at. 
34 | Muhammad Isnan Kualifikasi Sumber Daya Insani Berbasis Kompetensi dan Integritas...•

b) Problem solving yaitu kegiatan pengarahan (dalam bentuk obrolan santai) yang dilakukan oleh pemimpin atau kepala seksi dengan pegawainya untuk mencari pemecahan suatu masalah.

c) Pemberian pengarahan dari Kepala perusahaan setiap kesempatan.

d) Belajar sendiri, caranya adalah perusahaan membebaskan pegawainya untuk mencoba mempelajari pekerjaan diluar pekerjaannya dengan bartanya maupun meminta bimbingan. Misalnya Customer service menjadi Teller.

e) Mendatangkan penceramah untuk melakukan seminar atau ceramah-ceramah islami untuk penyejukan psikologi dan pengembangan kepribadian.

\section{2) Lectures}

Metode yang digunakan adalah lectures (kuliah) dengan cara penyajian informasi secara lisan. Pegawai diberikan tugas untuk memberikan presentasi atau ceramah yang bersifat tematis tentang pekerjaannya maupun tentang ilmu-ilmu spiritual (keagamaan). Hal ini memberikan pengaruh positif terhadap kemampuan presentasi, pengembangan diri, maupun kepercayaan diri pegawai.

\section{Simpulan}

Berdasarkan dari pemaparan diatas, disimpulkan bahwa pertama, sumber daya insani (SDI) di BMT Prima Lubuk Seberuk hampir keseluruhan di isi oleh sumber daya insani (SDI) yang lulusan sarjana umum/bukan syari'ah, dan sebagian terdiri dari pegawai lulusan tingkat menengah atas (SMA). BMT Prima Lubuk Seberuk telah membuka peluang kerja bagi lulusan sarjana syari'ah untuk bisa bekerja di lembaga BMT Prima Lubuk Seberuk, akan tetapi pada kenyataanya sampai saat ini BMT Prima Lubuk Seberuk belum mendapatkan pegawai yang berkualifikasi sarjana syariah. Kedua, Dalam upaya pegembangan sumber daya insani di BMT Prima menerapkan beberapa standar pengelolaan manajemen dengan menerapkan beberapa langkah strategis mulai dari proses perencanaan (planning), proses perekrutan (rekruitment), pemberian motivasi, dan proses pendidikan dan pelatihan. Untuk memenuhi kebutuhan pegawai yang berkualifikasi kompetensi dan integritas di BMT Prima yang mayoritas di isi oleh lulusan sarjana bukan syari'ah, BMT Prima memberikan pendidikan privat tentang keilmuan syari'ah dengan mengadakan pelatihan untuk meningkatkan kualitas 
ISLAMIC BANKING Volume 5 Nomor 1 Edisi Agustus 2019 | 35

Sumber daya insani (SDI) agar memahami tentang produk-produk di perbankan syari'ah.

\section{Saran}

Beberapa saran yang patut dipikirkan dan di eksekusi terutama dalam menentukan kualifikasi sumber daya insani yang berbasis kompetensi dan integritas untuk meningkatkan kualitas pegawai di lingkungan BMT Prima, yaitu:

1. Ppenting untuk merekrut para pegawai tepat dan memiliki disiplin ilmu pengetahuan terutama yang berhubungan dengan perkerjaan serta menempatkan pada posisi tepat (the right man on the right place) dengan tujuan untuk mempercepat adaptasi para pegawai dilingkungan lembaga keuangan syariah di BMT Prima agar tidak menjadi kendala dan menghambat kinerja di lingkungan kerja pegawai.

2. Dalam upaya meningkatkan pengembangan sumber daya insani di BMT Prima perlu adanya pelatihan pengembangan secara konsisten dan terarah agar mampu menghasilkan sumber daya insani yang kompeten dan berintegritas sesuai dengan bidang yang dikuasai sehingga tidak akan ada tindakan kecurangan dan sebagainya. 


\section{DAFTAR PUSTAKA}

Amri, Hoirul, "Membangun Kesadaran Masyarakat Pinggiran Melalui Baitul Maal Wat Tamwil (BMT), Islamic Banking, Volume 4, Nomor 1, Agustus 2018

Anoraga Pandji, Manajemen Bisnis, Cet.I Jakarta: PT.Rineka Cipta, 1997

Arif Syafrudin, “Need Assesment SDM Ekonomi Islam, ’'La_RibaVol. 01,No. 01, 2007

Ahmad Agus Safei Nanih Machendrawaty. Pengembangan Masyarakat Islam. Bandung: Rosdakarya,2001

Ancok, Djamaludin. Psikologi Islami. (Yogyakarta: Pustaka. Pelajar.1994), hlm.79 Al-Qur'an dan Terjemahnya, Jakarta: Rajawali Prest: 2009

Covey.Stephen M. R,The Speed of Trust. Dalam Ika Yunia Fauzia Dan Abdul Kadir Riyadi, Prinsip Dasar Ekonomi Islam Perspektif Maqashid Al-Syari'ah.Jakarta: Prenada Media Group, 2014

Jusmaliani, Pengelolaan Sumber Daya Insani, Jakarta: PT Bumi Aksara, 2011

Komaruddin. Ensiklopedia Manajemen. Jakarta: Penerbit Bumi Aksara, 2006

Muhammad, Petunjuk Pelaksanaan Pembukaan Kantor Bank Syariah,Jakarta: Rieneke, 2005

Muhammad, Metodologi Penelitian Pemikiran Ekonomi Islam, Yogyakarta: Ekonisia FE UII,2003

Moekijat, Manajemen Personalia Dan Sumber Daya Manusia, Bandung: Mandar Maju, 1995

Nawawi Hadari, Manajemen Strategik, Yogjakarta: Gajah mada Pers, 2005

Rivai Veithzal, Islamic Human Capital, Jakarta: Rajawali Pers, 2009

Robert L. Mathis-John H. Jackson. Human Resource Management, edisi 10, Jakarta: Salemba Empat, 2006

Ruky Achmad S., Sumber Daya Manusia Berkualitas, Jakarta :PT.Gramedia Pustaka Utama, 2006

Sastradipoera Komaruddin, Strategi Pembangunan Sumber Daya Berbasis Pendidikan Kebudayaan. Bandung : Kappa Sigma, 2006

Sanapiah Faisal, 2001. Format-Format Penelitian Sosial, Jakarta: Raja Grafindo Persada.

Suryani. Tatik Manajemen Koperasi Teknik Penyusunan Laporan Keuangan, Pelayanan Prima dan Pengelolaan SDM ,Yogyakarta: Graha Ilmu, 2008

Suwatno,Tjutju Yuniarsih, Manajemen Sumber Daya Manusia Teori, Aplikasi Dan Isu Penelitian, Yogyakarta: Ekonisia, 2003 
ISLAMIC BANKING Volume 5 Nomor 1 Edisi Agustus 2019 | 37

Hafidhuddin, Didin dan Henri Tanjung, 2003. Manajemen Syariah dalam Praktik, Jakarta: Gema Insani Press.

Wibowo, 2013. Manajemen Kinerja, Jakarta: PT. Rajagraindo Persada.

Zamzam, Fakhry dan Havis Aravik, 2016. Manajemen SDM Berbasis Syariah, Bogor: CV. RWTC Success 